\title{
Evaluation of non-palpable thyroid nodules by ultra sound guided fine needle aspiration cytology
}

\author{
Khalid Ahmad Al-Sindi ${ }^{1}$, Mulazim Hussain Bukhari ${ }^{2 \#}$, Kanwal Saba ${ }^{3}$, Wajid $\mathrm{Ali}^{3}$, \\ Madiha Arshad ${ }^{2}$, Nasir Raza Zaidi ${ }^{3}$ \\ ${ }^{1}$ Department of Pathology, King Hamad University Hospital, Al Sayh, Bahrain
2Department of Pathology King Edward Medical University, Lahore, Pakistan;
${ }^{\#}$ Corresponding Author: drmhbukhari@yahoo.com, mulazim.hussain@gmail.com
${ }^{3}$ Department of Radiology, Mayo Hospital/ King Edward Medical University, Lahore, Pakistan
}

Received 24 November 2012; revised 28 December 2012; accepted 9 January 2013

\section{ABSTRACT}

The aim of this study was to see the usefulness of fine needle aspiration by "the Bethesda system for reporting Thyroid Cytopathology" (TBSRTC) for non palpable thyroid nodules through ultrasound-guidance for the evaluation and treatment planning of nonpalpable thyroid lesions. This study was conducted on 200 patients with non palpable thyroid nodules which are very low lying or felt on swallowing; in Department of Pathology and Radiology since January 2011 to June 2012. The patients were scanned and USGFNAC was performed and reporting was done by "TBSRTC". Of the 200 specimens 17 samples were nondiagnostic or unsatisfactory (Class I), 145 samples were benign (Class II), 20 samples were showing Atypical of Undetermined Significance (AUS) or Follicular Lesion of Undetermined Significance (FLUS); (Class III), 6 were showing follicular neoplasm or suspicious for a follicular neoplasm (Class IV), 7 samples were suspicious for malignancy (Class $\mathrm{V}$ ) and 5 samples were positive for malignancy (Class VI). On comparison of ultrasound guided FNAC with histopathology the sensitivity for correct diagnosis was $93 \%$, specificity was $86 \%$, positive predictive value was $37 \%$, negative predictive value was $99 \%$ and accuracy was $86 \%$. USG-FNAC is a useful modality for the evaluation and treatment planning of nonpalpable thyroid lesions smaller than $5 \mathrm{~mm}$ in the maximum diameter. TBSRTC is the best method of reporting but class III and IV are the main pitfall of this system for reporting Thyroid Cytopathology and show high sensitivity, specificity and accuracy.

*Competing interest: No competing interest to declare by any of the authors.
Keywords: FNAC; USG; The Bethesda Classification; Follicular Adenoma; Follicular Carcinoma; Papillary Carcinoma; Medullary Carcinoma

\section{INTRODUCTION}

Thyroid nodules are becoming an epidemic problem in the world in the general population, however the thyroid malignancy is rare among these swellings [1-3].

Thyroid tumors are more common in females as compared to males with annual worldwide with male to female ration 1:2.6 [2].

The larger thyroid swellings are not a problem to aspirate and detect through biopsy but smaller or deeper nodules are difficult to diagnose early. These nodules may cause the danger of occult carcinoma. In the literature diverse and contradictory approaches have been suggested for the management of non-palpable thyroid nodules [4].

Ultrasonography (US) is increasingly able to detect thyroid nodules, and the differentiation between malignant and benign nodules has been raising issues among both clinicians and patients, especially patients with nonpalpable small nodules [5,6]. It is important to diagnose thyroid cancer at an early stage, because it may reduce the risk of disease recurrence and possible mortality. Fine-needle cytology appears to be a useful diagnostic tool also for nodules of less than $1 \mathrm{~cm}$ because the percentage of unsatisfactory results is not related to the size of the nodule $[7,8]$.

Study was conducted to evaluate a non-Palpable thyroid nodule through Ultra sound guided thyroid fine needle aspiration cytology (US-FNAC).

\section{MATERIAL AND METHODS}

This study was conducted on 200 (36 males, 164 fem- 
ales) patients with an age range of 10 - 70 years, in the Department of Radiology, Nuclear Medicine and Department of Pathology since January 2011 to June 2012.

A written "informed consent" was taken from patients before performing Ultrasound guided fine needle aspiration Cytology (US-FNACs). The study was approved by ethical committee of the University. The FNACs and FNAB samples (Preoperated US-FNAC on admitted patients) were collected from patients presented for a thyroid nodule after evaluation by thyroid function tests and thyroid scans. Fine Needle biopsy or lobectomy was followed for histopathology, which was considered as a gold standard to compare the results of these FNAC with the final histopathological reports (Fine needle biopsies and lobotomies), therefore the patients were followed for their biopsies that underwent surgery at our Hospital or Fine needle biopsies.

\subsection{Cytopathological Reporting Criteria}

Bethesda method was used to report the cytopathology of thyroid aspirates as six classes $[9,10]$.

1) Nondiagnostic or Unsatisfactory: Cyst fluid only virtually acellular specimen (obscuring blood, clotting artifact, etc).

2) Benign: Consistent with a benign follicular nodule (includes adenomatoid nodule, colloid nodule, etc) consistent with lymphocytic (Hashimoto) thyroiditis in the proper clinical context consistent with granulomatous (subacute) thyroiditis.

3) Atypica of Undetermined Significance or Follicular Lesion of Undetermined Significance.

4) Follicular Neoplasm or Suspicious for a Follicular Neoplasm Specify if Hürthle cell (oncocytic) type.

5) Suspicious for Malignancy: Suspicious for papillary carcinoma, Suspicious for medullary carcinoma, Suspicious for metastatic carcinoma, Suspicious for lymphoma.

6) Malignant: Papillary thyroid carcinoma, Poorly differentiated carcinoma, Medullary thyroid carcinoma, Undifferentiated (anaplastic) carcinoma, Squamous cell carcinoma, Carcinoma with mixed features (specify), Metastatic carcinoma, Non-Hodgkin lymphoma.

\subsection{Inclusion Criteria}

1) Age 10 to 70 Years;

2) Both genders;

3) Preoperated US-FNAC on admitted patients;

4) Non palpable nodules size $5 \mathrm{~mm}$ - $10 \mathrm{~mm}$ in maximum diameter (evaluated after thyroid scan).

\subsection{Exclusion Criteria}

1) Patients with already diagnosed thyroid lesions;

2) All toxic goiters confirmed by clinical evaluation.

\subsection{Evaluation of Patients}

Patients presenting with some clinical symptoms related to thyroids were performed scan, thyroid function tests and ultrasonography. Measure serum TSH in the initial evaluation of a patient with a thyroid nodule. If the serum TSH is subnormal, a radionuclide thyroid scan should be performed using either technetium 99 m Tc pertechnetate or ${ }^{123}$ I. Patients with non palpable thyroid nodules (according to inclusion criteria) in the OPD and fulfilling the inclusion criteria were included in this study. Informed consent from all the patients included in the study was taken. All the patients were recorded for their demographic features, that is, age, sex, and address (for follow up). History of present illness with regard to symptoms and duration was recorded. They were examined for the signs related to the solitary thyroid swelling. All routine investigations and serum T3, T4, and TSH levels were performed by radioimmunoassay (RIA), (normal range of T3, 2.5 - $5.8 \mathrm{pmol} / \mathrm{L}$, T4, 11.5 - $23.0 \mathrm{pmol} / \mathrm{L}$, and TSH, 0.5 - $5.0 \mathrm{mU} / \mathrm{L}$ ). Patients with thyroid swelling underwent thyroid scan. Thyroid swellings were marked through by nuclear department and then FNAC was performed [11].

\subsection{USG Reporting Criteria for Thyroid Nodules}

High-resolution thyroid ultrasonography (USG) will be used as a diagnostic modality for haunting the nonpalpable thyroid nodules. These characteristics of thyroid nodules that would be studied included microcalcifications, an irregular or microlobulated margins, marked hypoechogenicity, a shape that was taller than it was wide and color flow pattern in Color Doppler ultrasound. The presence and absence of characteristics of nodules will be classified as having positive or negative findings. If even one of these USG features will be presented, the nodule will be classified as positive (malignant). If a nodule has none of the features described, it will be classified as negative (benign). The final diagnosis of a lesion as benign or malignant will be confirmed by fine needle aspiration cytology and biopsy [12-15] (Figure 1).

\subsection{Method of USG FNAC}

An experienced radiologist performed an ultrasonographic fine needle aspitaion (USG-FNAC) with the use $10 \mathrm{ml}$ disposable syringe of (BD Company) with 23-gauge needle by using a perpendicular puncture and without local anesthesia. When the needle tip reached the target nodule, the needle was observed as a small echogenic spot within the nodule on the US monitor. After the needle tip was placed in the appropriate area of the target nodule, sampling was commenced using the "mixed sampling technique”. This technique is an individual sampling 
technique where the needle is moved up and down for a few seconds only by movement of the wrist of the operator and without initial aspiration under US guidance. In all cases, only one sampling by one puncture was taken from each nodule. After a sample was obtained, the specimen was mounted immediately onto a glass slide. We obtained four to six slides by performing two or three smears from each nodule. Specimens were fixed with 95\% ethanol and were sent for pathological evaluation [11,16] (Figure 1).

\section{RESULTS}

The mean age of the patients was $33.35 \pm 11.77$ and male to female ratio was 1:4.5 and most of the patients were from younger group ranging from 21 - 40 (Table 1).

Of the 200 specimens on FNACs, 17 samples (8.5\%) were non-diagnostic or unsatisfactory for diagnosis (Class I), 145 (72.5\%) were benign (Class II), 20 (10\%) cases were of follicular neoplasm or suspicious for a follicular neoplasm (Class III), 6 (3\%) smears were showing atypia of undetermined significance or follicular lesion of undetermined significance (Class IV), 7 (3.5\%) smears were of suspicious for malignancy and 5 (2.5\%) cases were malignant lesions of thyroid (Tables 2, 4 and 5). There were 24 false positive cases from correct diagnosis and only 1 smear was false negative when compared with histopathology biopsy (Table 3).

On histopathological examination of these smears, there were $15 / 200$ (7.5\%), cases malignant thyroid lesions; $10 / 15$ (66.6\%) cases were papillary carcinomas, $4 / 15(26.6 \%)$ cases were follicular carcinomas and 1/14 (6.6\%) case was of medullary carcinomas (Table 4).

Of 168/200 (84\%) benign specimens; there were 25/ 168 (15\%) follicular adenomas, 119/158 (71\%) specimens were multinodular goiters, 20/168 (12\%) cases were of colloid goiter and 4/168 (2\%) specimens were of Hashimoto thyroiditis. Of the Class III smears only 1 case (follicular carcinoma) was found malignant and 18 cases were of follicular adenomas on histopathology (Table 5).

The comparison of other classes is given in Table 2. On FNAC, the clear cut malignant smears were 5/200 (2.5\%), $7 / 200$ smears were showing suspicious smears, $6 / 200$ and 20/200 smears created impact of undetermined morphology, while on histopathology, there were $15 / 200$ (7.5\%) specimens proved to be malignant (Tables 1 and 3). All the false positive smears were found follicular adenoma (Table 1, Figures 2-5).

On cytohistologic correlation, the sensitivity was $93 \%$, specificity was $86 \%$, positive predictive value was $37 \%$, negative predictive value was $99 \%$ and accuracy was $86 \%$. The false negative specimen was papillary thyroid carcinoma which was improperly aspirated from targeted nodules and was diagnosed as benign lesions (Tables 2 and 3).
Table 1. Distribution of subjects by age and sex.

\begin{tabular}{cccc}
\hline \multirow{2}{*}{ Age } & \multicolumn{2}{c}{ Number1:4 } & Percentage \\
\cline { 2 - 3 } & Male 36 & Females 164 & \\
\hline $10-20$ & 2 & 8 & 10 \\
$21-30$ & 12 & 69 & 81 \\
$31-40$ & 10 & 56 & 66 \\
$41-50$ & 6 & 17 & 23 \\
$51-60$ & 4 & 9 & 13 \\
$61-70$ & 2 & 5 & 7 \\
Total & 36 & 164 & 200 \\
Mean \pm SD & & $33.35 \pm 11.77$ & \\
Male to female ration & & $1: 4.5$ & \\
\hline
\end{tabular}

Table 2. Distribution of different lesions diagnosed by histopathologists.

\begin{tabular}{|c|c|c|c|c|}
\hline \multirow{2}{*}{$\begin{array}{l}\text { Group B } \\
\text { Classes }\end{array}$} & \multirow{2}{*}{$\begin{array}{c}\text { FNA by USG } \\
\text { Numbers }\end{array}$} & \multicolumn{3}{|c|}{ Histopathology } \\
\hline & & \multicolumn{2}{|c|}{ Benign } & \multirow{2}{*}{$\begin{array}{c}\text { Malignant } \\
\text { Not } \\
\text { operated }\end{array}$} \\
\hline & $\begin{array}{l}\text { Non-diagnostic } \\
\text { or Unsatisfactory }\end{array}$ & 17 (8.5\%) & $\begin{array}{c}\text { Not } \\
\text { operated }\end{array}$ & \\
\hline II & Benign & 145 (72.5\%) & 144 & 1 (PTC) \\
\hline III & $\begin{array}{l}\text { Follicular Neoplasm } \\
\text { or Suspicious for a } \\
\text { Follicular Neoplasm }\end{array}$ & 20 (10\%) & $\begin{array}{c}18 \\
(\mathrm{FA})\end{array}$ & 2 (FTC) \\
\hline IV & $\begin{array}{l}\text { Atypia of Undetermined } \\
\text { Significance or Follicular } \\
\text { Lesion of Undetermined } \\
\text { Significance }\end{array}$ & $6(3 \%)$ & $4(\mathrm{FA})$ & 2 (FTC) \\
\hline $\mathrm{V}$ & $\begin{array}{l}\text { Suspicious for } \\
\text { Malignancy }\end{array}$ & 7 (3.5\%) & $\begin{array}{c}2 \\
(\mathrm{FA})\end{array}$ & 5 (PTC) \\
\hline VI & Malignant & $5(2.5 \%)$ & 0 & $\begin{array}{c}4 \text { (PTC) } \\
\text { and } 1 \text { (MTC) }\end{array}$ \\
\hline Total & & 200 & $\begin{array}{c}168 \\
(84 \%)\end{array}$ & 15 (7.5\%) \\
\hline
\end{tabular}

Key PTC: papillary thyroid carcinoma, FA: follicular adenomas, MTC medullary thyroid carcinoma, FTC: follicular thyroid carcinoma.

Table 3. Comparison of FNAC of with histopathology.

\begin{tabular}{cccc}
\hline Cytopathology & \multicolumn{3}{c}{ Histopathology } \\
\hline FNAC + ve & 14 & 024 & 038 \\
FNAC - ve & 01 & 144 & 145 \\
Total & 15 & 168 & 183 \\
\hline
\end{tabular}

Sensitivity: $93 \%$, specificity: $86 \%$, positive predictive value: $37 \%$, negative predictive value $99 \%$, accuracy: $86 \%$. 
Table 4. Distribution of malignant lesions on histopathology.

\begin{tabular}{ccc}
\hline $\begin{array}{c}\text { Malignant } \\
\text { Lesions } \\
(\mathrm{n}=15: 7.5 \%)\end{array}$ & Numbers & Percentage \\
\hline Papillary carcinoma & 10 & $66.6 \%$ \\
Follicular carcinoma & 4 & $26.6 \%$ \\
Medullary carcinoma & 1 & $6.6 \%$ \\
Total & 15 & 100 \\
\hline
\end{tabular}

Note: Non-palpable nodules have lower prevalence of malignancy as compared to palpable one in our country.

Table 5. Distribution of benign lesions on histopathology.

\begin{tabular}{ccc}
\hline $\begin{array}{c}\text { Benign Lesions } \\
(\mathrm{n}=168: 84 \%)\end{array}$ & Numbers & Percentage \\
\hline $\begin{array}{c}\text { Follicular Adenoma } \\
\text { (20 = Follicular adenoma } \\
\text { and 5 Hurthle cell lesions })\end{array}$ & 25 & $15 \%$ \\
Multinodular goiters & 20 & $12 \%$ \\
Colloid goiters & 119 & $71 \%$ \\
Hoshiomot's thyroiditis & 04 & $02 \%$ \\
Total & 168 & 100 \\
\hline
\end{tabular}

Note: Most of the non-palpable nodules were found benign (84\%).

\section{DISCUSSION}

Ultrasound guided fine needle aspiration technique is anon-invasive, simple and an accurate modality to evaluate a non-palpable thyroid nodular nodule. The American Thyroid Association (ATA) guidelines suggest that, in general, only nodules larger than $10 \mathrm{~mm}$ in diameter should be evaluated as the nodules having the potential to represent a clinically significant cancer [17]. Sometimes occult carcinoma may arise from the nodules less than $10 \mathrm{~mm}$ therefore a careful evaluation is necessary from the patients with these smaller lesions $[18,19]$.

In this study, the sensitivity and negative predictive value of performing an US-FNAC for the diagnosis of non-palpable thyroid nodules were high as compared

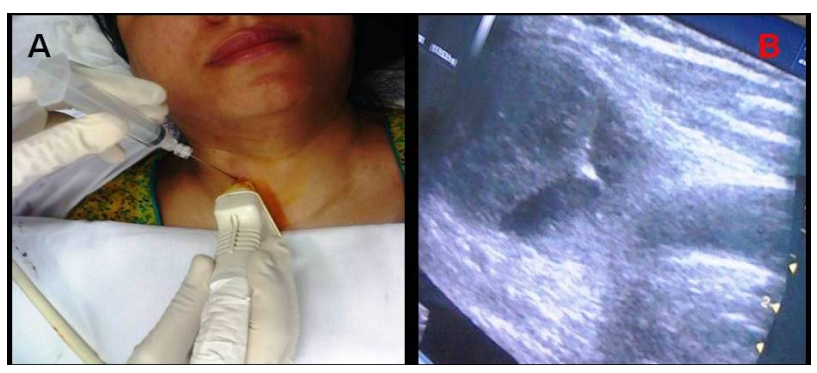

Figure 1. (A) Photograph of the patients, USG and needle positions for FNAC of thyroid lesions; (B) USG picture showing needle entry in the thyroid nodule.

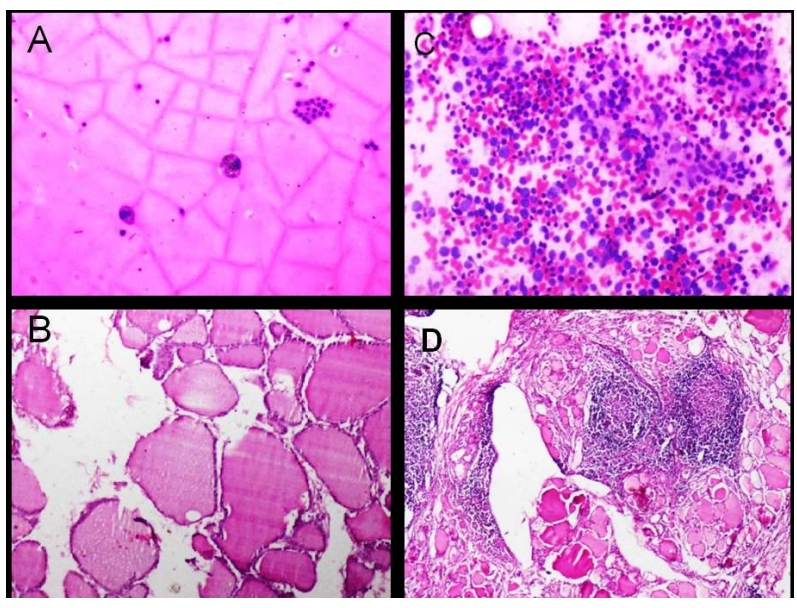

Figure 2. Photomicrograph of (A) (H\&E 20×), The Bethesda System for reporting Thyroid Cytopathology (TBSRTC) Class II smear with colloid back ground, macrophages and follicular cells (TB); (B) On histopathology (H\&E 20×) of colloid goiter; (C) TBSRTC Class II smear, with hurthle cells and lymphocytes (H\&E 20×); (D) Hashimoto’s thyroiditis.

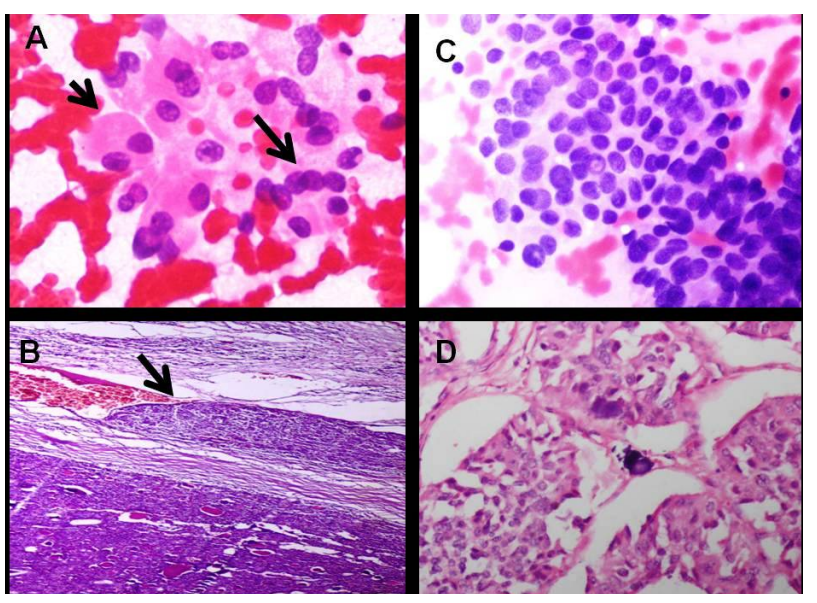

Figure 3. Photomicrograph of (A) (H\&E 20×), The Bethesda system for reporting Thyroid Cytopathology (TBSRTC) Class III smear atypical arrangement of follicular cells (long arrow) and few hurtle cells (small arrow); (B) On histopathology (H\&E $20 \times$ ) Follicular Carcinoma with vascular invasion (arrow); (C) TBSRTC Class V (Suspicious for malignancy) smear showing two of the features of papillary carcinoma (H\&E 20×); (D) Papillary Carcinoma with ground glass nuclei and psamaoma bodies.

with values obtained for other studies; however, positive predictive value was low [16].

The small positive predictive value $(\mathrm{PPV}=37 \%)$ indicates that many of the positive results from this testing procedure are false positives. Thus it will be necessary to follow up any positive result with a more reliable test (Histopathology) to obtain a more accurate assessment as to whether cancer is presented. Nevertheless, such a test may be useful if it is inexpensive and convenient. Therefore in this test sensitivity and specificity should be used to detect the reliability of FNAC. In our data, the 


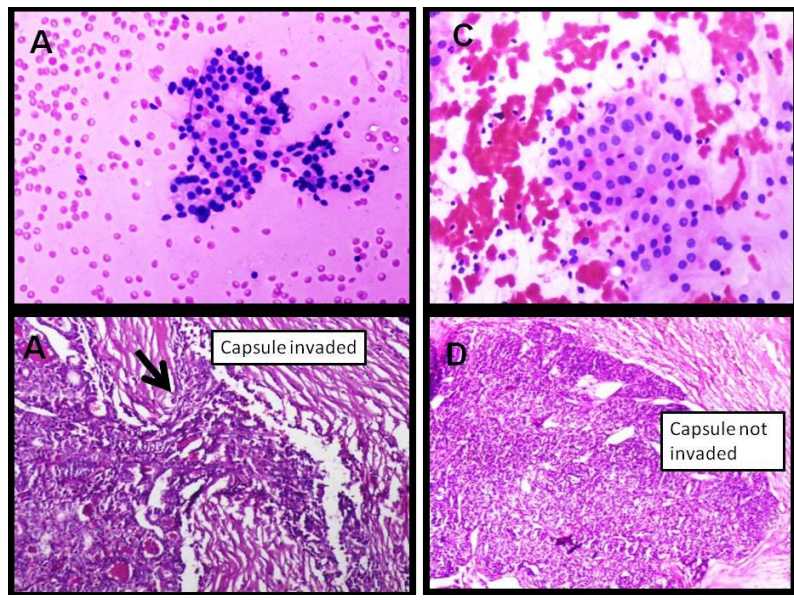

Figure 4. Photomicrograph of (A) (H\&E 20×), The Bethesda system for reporting Thyroid Cytopathology (TBSRTC) Class IV smear follicular cells against scanty colloid; (B) On histopathology (H\&E 20×) follicular carcinoma with capsular invasion (Arrow); (C) TBSRTC Class IV (follicular cells against scanty colloid) smear showing (H\&E 20×); (D) Follicular adenoma (False positive lesions).

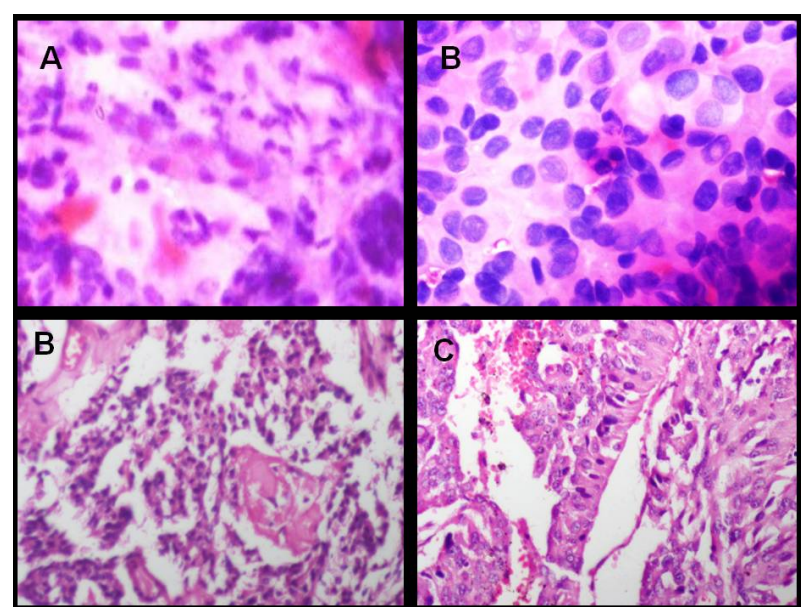

Figure 5. Photomicrograph of (A) (H\&E 20×), The Bethesda system for reporting Thyroid Cytopathology (TBSRTC) Class VI (malignant) smear, showing round and spindle cells with giant cells; (B) On histopathology (H\&E 20×) medullary carcinoma; (C) TBSRTC Class VI (malignancy) smear (H\&E 20×) showing all features of papillary carcinoma (overlaping, groves, inclusions,ground and smuged chromatic); (D) Tall columnar cell variant papillary carcinoma.

sensitivity was $93 \%$, specificity was $86 \%$, positive predictive value was $37 \%$, negative predictive value was $99 \%$ and accuracy was $86 \%$. The false negative specimen was papillary thyroid carcinoma which was improperly aspirated from targeted nodules and was diagnosed as benign lesions.

We categorized cytological results into five classes according to Bethesda description for thyroid cytology. Such categorization of FNAC smears results is necessary to allow clinicians to use cytology results to guide patient management with specific reference to the need for thyroidectomy [20].

With USG FNAC, the sensitivity was $93 \%$, specificity was $86 \%$, positive predictive value was $37 \%$ and negative predictive value was $99 \%$. According to our reports patients of Classes III-VI underwent thyroid surgery.

None of them were showing any distance metastasis or lymph node involvement and only 15/200 (7.5\%) cases showed true positivity. There were only 10 cases of papillary thyroid carcinoma, while only 4 cases were suffering from follicular carcinoma and one case was found to be medullary carcinoma. None of these cases were showing multifocality or bilateralism. These findings are also different from Kim et al. [16]. The justification of our findings is that we performed our study on $5-10 \mathrm{~mm}$ nodules. Our findings show that ignorance of these small lesions may lead to spread of carcinoma to distance organs while early management proves to better prognosis and long survival of these patients.

Our study showed that use of better reporting system (Bethesda methods) there was relatively low rate of non diagnostic or inadequate smears, allowing it to be useful method for determining the treatment plan for non palpable smaller thyroid nodules. In our study the incidence of adequate specimens was 183/200 (91.5\%) with USFNAC as compared to the Kim et al who found it $81 \%$ in his series of 201 patients [16].

\section{CONCLUSION}

USG-FNAC is a useful modality for the evaluation and treatment planning of nonpalpable thyroid lesions smaller than $5 \mathrm{~mm}$ in the maximum diameter. TBSRTC is the best method of reporting but class III and IV are the main pitfall of this system for reporting Thyroid $\mathrm{Cy}$ topathology and shows high sensitivity, specificity and accuracy

\section{JUSTIFICATION OF STUDY}

Thyroid nodules are very common in the general population, but malignancy is relatively rare. The goal of the ultrasound guided evaluation of nonpalpable thyroid nodules by FNAC is the early detection of lesions and to save the overt spread of malignancies, while identifying and avoiding unnecessary surgery in those with benign, asymptomatic thyroid nodules. UGS is very helpful in locating the non-palpable thyroid nodules for FNAC and increases the quality of diagnosis which is helpful for the clinical management of such patients. Our study showed good sensitivity, specificity for US-FNAC with relatively low rate of non diagnostic or inadequate smears.

\section{LIMITATIONS OF THE STUDY}

The study was only on 200 cases and it should be done 
as cohort one on a large scale study. The high false rate was our limitation for reporting the Classes III and IV lesions with Bethesda methods that needs more training of cytopathologists. We could not control some of our confounding factors like underlying diffuse thyroid disease which influenced the outcome of the US-FNACs like thyroiditis and diffuse colloid disease but we excluded the hot nodules to overcome negative influences on our study. In our study we did not follow the patients with inadequate swellings and we could not convince the surgeons for delaying the surgery for Class II smears (Benign). Classes III and IV are the main pitfall of The Bethesda System for reporting Thyroid Cytopathology (TBSRTC).

\section{IMPORTANCE OF THIS STUDY}

The evaluations of these smaller nodules for the early diagnosis of thyroid cancers with ultrasound guided FNAC were helpful for detection of $7 \%$ malignant thyroid lesions. These techniques will be fruitful to improve patient outcome and selection of treatment modalities (e.g., a lobectomy or total thyroidectomy or delaying the surgery option) and will save for distance metastasis and progressing to high grade anaplastic or poorly differentiated thyroid carcinomas.

\section{ACKNOWLEDGEMENTS}

We are thankful to the support of Radiological Department and Pathology Department of King Edward Medical University.

\section{REFERENCES}

[1] Anil, G., Hegde, A. and Chong, F.H. (2011) Thyroid nodules: Risk stratification for malignancy with ultrasound and guided biopsy. Cancer Imaging, 11, 209-223.

[2] Ghassi, D. and Donato, A. (2009) Evaluation of the thyroid nodule. Postgraduate Medical Journal, 85, 190-195. doi:10.1136/pgmj.2008.072140

[3] Sclabas, G.M., Staerkel, G.A., Shapiro, S.E., Fornage, B. D., Sherman, S.I., Vassillopoulou-Sellin, R., et al. (2003) Fine-needle aspiration of the thyroid and correlation with histopathology in a contemporary series of 240 patients. The American Journal of Surgery, 186, 702-709. doi:10.1016/j.amjsurg.2003.08.015

[4] Accurso, A., Rocco, N., Palumbo, A. and Leone, F. (2005) Usefulness of ultrasound-guided fine-needle aspiration cytology in the diagnosis of non-palpable small thyroid nodules. Tumori, 91, 355-357.

[5] Khurana, K.K., Richards, V.I., Chopra, P.S., Izquierdo, R., Rubens D. and Mesonero, C. (1998) The role of ultrasonography-guided fine-needle aspiration biopsy in the management of nonpalpable and palpable thyroid nodules. Thyroid, 8, 511-515. doi:10.1089/thy.1998.8.511

[6] Rago, T. and Vitti, P. (2008) Role of thyroid ultrasound in the diagnostic evaluation of thyroid nodules. Best Practice \& Research: Clinical Endocrinology \& Metabolism, 22, 913-928. doi:10.1016/j.beem.2008.09.016

[7] Kwak, J.Y., Kim, E.K., Kim, M.J. and Son, E.J. (2009) Significance of sonographic characterization for managing subcentimeter thyroid nodules. Acta Radiologica, 50, 917-923. doi:10.1080/02841850903062724

[8] Frates, M.C., Benson, C.B., Charboneau, J.W., Cibas, E.S., Clark, O.H., Coleman, B.G., et al. (2005) Management of thyroid nodules detected at US: Society of radiologists in ultrasound consensus conference statement. Radiology, 237, 794-800. doi:10.1148/radiol.2373050220

[9] Cibas, E.S. and Ali, S.Z. (2009) The Bethesda system for reporting Thyroid Cytopathology. American Journal of Clinical Pathology, 132, 658-665. doi:10.1309/AJCPPHLWMI3JV4LA

[10] Wong, L.Q. and Baloch, Z.W. (2012) Analysis of the Bethesda system for reporting Thyroid Cytopathology and similar precursor Thyroid Cytopathology reporting schemes. Advances in Anatomic Pathology, 19, 313-319. doi:10.1097/PAP.0b013e3182666398

[11] Basharat, R., Bukhari, M.H., Saeed, S. and Hamid, T. (2011) Comparison of fine needle aspiration cytology and thyroid scan in solitary thyroid nodule. Pathology Research International, 2011, Article ID: 754041.

[12] Cai, X.J., Valiyaparambath, N., Nixon, P., Waghorn, A., Giles, T. and Helliwell, T. (2006) Ultrasound-guided fine needle aspiration cytology in the diagnosis and management of thyroid nodules. Cytopathology, 17, 251-256. doi:10.1111/j.1365-2303.2006.00397.x

[13] Robinson, I.A. and Cozens, N.J. (1999) Does a joint ultrasound guided cytology clinic optimize the cytological evaluation of head and neck masses? Clinical Radiology, 54, 312-316. doi:10.1016/S0009-9260(99)90561-5

[14] Kovacevic, D.O. and Skurla, M.S. (2007) Sonographic diagnosis of thyroid nodules: Correlation with the results of sonographically guided fine-needle aspiration biopsy. Journal of Clinical Ultrasound, 35, 63-67. doi:10.1002/jcu.20287

[15] Papini, E., Guglielmi, R., Bianchini, A., Crescenzi, A., Taccogna, S., Nardi, F., et al. (2002) Risk of malignancy in nonpalpable thyroid nodules: Predictive value of ultrasound and color-Doppler features. The Journal of Clinical Endocrinology \& Metabolism, 87, 1941-1946. doi:10.1210/jc.87.5.1941

[16] Kim, D.W., Park, A.W., Lee, E.J., Choo, H.J., Kim, S.H., Lee, S.H., et al. (2009) Ultrasound-guided fine-needle aspiration biopsy of thyroid nodules smaller than $5 \mathrm{~mm}$ in the maximum diameter: Assessment of efficacy and pathological findings. Korean Journal of Radiology, 10, 435-440. doi:10.3348/kjr.2009.10.5.435

[17] Gharib, H., Papini, E., Valcavi, R., Baskin, H.J., Crescenzi, A., Dottorini, M.E., et al. (2006) American Association of Clinical Endocrinologists and Associazione Medici Endocrinologi medical guidelines for clinical practice for the diagnosis and management of thyroid nodules. Endocrine Practice, 12, 63-102.

[18] Cooper, D.S., Doherty, G.M., Haugen, B.R., Kloos, R.T., Lee, S.L., Mandel, S.J., et al. (2009) Revised American 
Thyroid Association management guidelines for patients with thyroid nodules and differentiated thyroid cancer. Thyroid, 19, 1167-1214. doi:10.1089/thy.2009.0110

[19] Cooper, D.S., Doherty, G.M., Haugen, B.R., Kloos, R.T., Lee, S.L., Mandel, S.J., et al. (2006) Management guidelines for patients with thyroid nodules and differentiated thyroid cancer. Thyroid, 16, 109-142. doi:10.1089/thy.2006.16.109

[20] Bongiovanni, M., Spitale, A., Faquin, W.C., Mazzucchelli, L. and Baloch, Z.W. (2012) The Bethesda system for reporting Thyroid Cytopathology: A meta-analysis. Acta Cytologica, 56, 333-339. doi:10.1159/000339959 